\title{
Assessment of the estrogenic activities of chickpea (Cicer arietinum L) sprout isoflavone extract in ovariectomized rats
}

Hai-rong MA ${ }^{1}$, Jie WANG ${ }^{1,2}$, Hong-xue $\mathrm{QI}^{1}$, Yan-hua GAO ${ }^{1}$, Li-juan PANG ${ }^{3}, Y_{i}$ YANG $^{1}$, Zhen-hua WANG ${ }^{2}$, Ming-jun DUAN ${ }^{4}$, Hua $\mathrm{CHEN}^{1}, \mathrm{Xu} \mathrm{CAO}^{5}$, Haji Akber AISA ${ }^{1, *}$

${ }^{1}$ Xinjiang Key Laboratory of Plant Resources and Natural Products Chemistry, Xinjiang Technical Institute of Physics and Chemistry, Chinese Academy of Sciences, Urumqi 830011, China; ${ }^{2}$ Key Laboratory of Xinjiang Endemic Phytomedicine Resources, Ministry of Education, College of Pharmacy, Shihezi University, Shihezi 832002, China; ${ }^{3}$ School of Medicine, Shihezi University, Shihezi 832002, China; ${ }^{4}$ Animal Experimental Center, The First Teaching Hospital of Xinjiang Medical University, Urumqi 830011, China; ${ }^{5}$ Department of Orthopaedic Surgery, Johns Hopkins University, School of Medicine Baltimore, MD 21205, USA

Aim: Chickpea (Cicer arietinum L) is a traditional Uighur herb. In this study we investigated the estrogenic activities of the isoflavones extracted from chickpea sprouts (ICS) in ovariectomized rats.

Methods: Ten-week-old virgin Sprague-Dawley female rats were ovariectomized (OVX). The rats were administered via intragastric gavage 3 different doses of ICS $\left(20,50\right.$, or $\left.100 \mathrm{mg} \cdot \mathrm{kg}^{-1} \cdot \mathrm{d}^{-1}\right)$ for 5 weeks. Their uterine weight and serum levels of $17 \beta$-estradiol $\left(E_{2}\right)$, follicle stimulating hormone (FSH) and luteinizing hormone ( $\mathrm{LH})$ were measured. The epithelial height, number of glands in the uterus, and number of osteoclasts in the femur were histologically quantified, and the expression of proliferating cell nuclear antigen (PCNA) was assessed immunohistochemically. Bone structural parameters, including bone mineral density (BMD), bone volume/tissue volume (BV/TV), trabecular thickness (Tb.Th) and trabecular separation (Tb.Sp) were measured using Micro-CT scanning.

Results: Treatments of OVX rats with ICS (50 or $100 \mathrm{mg} \cdot \mathrm{kg}^{-1} \cdot \mathrm{d}^{-1}$ ) produced significant estrogenic effects on the uteruses, including the increases in uterine weight, epithelial height and gland number, as well as in the expression of the cell proliferation marker PCNA. The treatments changed the secretory profile of ovarian hormones and pituitary gonadotropins: serum $\mathrm{E}_{2}$ level was significantly increased, while serum LH and FSH levels were decreased compared with the vehicle-treated OVX rats. Furthermore, the treatments significantly attenuated the bone loss, increased BMD, BV/TV and Tb.Th and decreased Tb.Sp and the number of osteoclasts. Treatment of OVX rats with the positive control drug $\mathrm{E}_{2}\left(0.25 \mathrm{mg} \cdot \mathrm{kg}^{-1} \cdot \mathrm{d}^{-1}\right)$ produced similar, but more prominent effects.

Conclusion: ICS exhibits moderate estrogenic activities as compared to $E_{2}$ in ovariectomized rats, suggesting the potential use of ICS for the treatment of menopausal symptoms and osteoporosis caused by estrogen deficiency.

Keywords: chickpea; chickpea sprout isoflavone; phytoestrogen; 17ß-estradiol; ovariectomized rat; uterine; follicle stimulating hormone; luteinizing hormone; osteoporosis

Acta Pharmacologica Sinica (2013) 34: 380-386; doi: 10.1038/aps.2012.160; published online 21 Jan 2013

\section{Introduction}

Peri- and postmenopausal syndromes in middle-aged and elderly women are marked by brief flushes, mood swings, dry skin, sleep disorders and joint pain, which are closely related to the lack of ovarian hormones ${ }^{[1]}$. A significant decrease in estrogen levels in women during the menopausal period also causes osteoporosis, a major public health concern. When the

\footnotetext{
* To whom correspondence should be addressed.

E-mail: haji@ms.xjb.ac.cn (Haji Akber AISA);

xcao11@jhmi.edu (Xu CAO)

Received 2012-08-01 Accepted 2012-10-21
}

bone resorption of osteoclasts outpaces the bone formation of osteoblasts during menopause, bone density is decreased and osteoporosis becomes more severe ${ }^{[2]}$. Epidemiological studies indicate that menopausal syndrome and osteoporosis caused by estrogen deficiency are the two major leading factors affecting the health and life quality of climacteric women ${ }^{[3]}$. Although hormone replacement therapy (HRT) can help to prevent and treat the menopausal syndromes, the side effects of HRT, such an increased risk of developing breast and endometrial cancer, prevent the acceptance of $\mathrm{HRT}^{[4,5]}$. Recently, reliable evidence has indicated that phytoestrogens offer the 
best potential therapy for menopausal women because they are safe and have a high compliance rate ${ }^{[6,7]}$. Increasing numbers of women are using phytoestrogens as an alternative therapy for menopausal syndromes. For example, isoflavones isolated from soy and red clover ${ }^{[8]}$, as well as extracts from such Chinese herbs as Asian ginseng (Panax ginseng) ${ }^{[9]}$ and dong-quai (Angelica sinensis) ${ }^{[10]}$, are popular commercial products that are widely used by women.

Cicer arietinum $\mathrm{L}$ is one of the oldest and most widely planted legumes in the world. Its common name (chickpea) was derived because its seed is spiry, like an eagle's beak. The chickpea has been a traditional Uighur herb for over 2500 years in Xinjiang, China, and it is an important food because it is rich in high-quality protein, carbohydrates and essential mineral elements ${ }^{[11]}$. Chickpeas have also been widely used in traditional Uighur medicine to treat and prevent hypertension, hyperlipidemia, diabetes, itchy skin, flatulence, low libido, tumor formation and osteoporosis ${ }^{[12]}$.

Isoflavones are important components in chickpea seeds and sprouts. They contain at least the following 8 phytoestrogens: biochanin A, formononetin, genistein, biochanin A-7-O$\beta$-D-glucoside, calycosin, trifolirhizin, ononin, and sissotrin ${ }^{[13]}$. In a recent study, we found that the level of isoflavones in chickpea sprouts was substantially higher compared to their levels in chickpea seeds ${ }^{[14,15]}$. Three of these isoflavones, biochanin A, formononetin and biochanin A-7-O- $\beta-D$-glucoside, can also be found in Trifolium pratense (red clover), which has been reported to exhibit strong estrogenic effects, including stimulating uterine growth and preventing bone loss ${ }^{[16]}$. Using a cotransfection-based screening method for phytoestrogen active constituents, we found that isoflavones extracted from chickpea sprouts (ICS) stimulated estrogen responsive element (ERE)-promoter activity in cells, and concurrent treatment with the nonselective estrogen receptor antagonist ICI 182,780 abolished the estrogenic activity induced by ICS. These in vitro results suggest that the estrogenic activity might be induced by isoflavones in $\operatorname{ICS}^{[17]}$. However, no direct evidence has shown that ICS can induce estrogenic effects in ovariectomized (OVX) rats.

In this study, we used an OVX rat model to study the potential estrogenic activities of ICS. We studied the effects of ICS treatment on uterine growth, ovarian hormone, gonadotropin responses and bone structural changes in OVX rats. Our study shows for the first time that ICS exhibits strong estrogenic activity and prevents bone loss in OVX rats. These results indicate that ICS is beneficial for the treatment of menopausal symptoms and osteoporosis caused by estrogen deficiency.

\section{Materials and methods}

\section{Chickpea sprout isoflavone extract (ICS) preparation}

The fresh chickpea seeds were soaked by submerging them in tap water in a plastic container with a washing device at $30^{\circ} \mathrm{C}$ for $2 \mathrm{~h}$. Sprouting took place in the dark using $200 \mathrm{~g}$ of seeds in a dish lined with filter paper. The temperature of the dish was maintained at $30^{\circ} \mathrm{C}$. Distilled water was sprayed for $30 \mathrm{~s}$ every $5 \mathrm{~h}$ during germination. The sprouted seeds were washed, and their water was changed twice a day for $5 \mathrm{~d}$ to avoid microbial growth. After $5 \mathrm{~d}$, the sprouts were collected from the fresh sprouted chickpea seeds. The sprouts were crushed and extracted three times with $70 \%$ ethanol $(m / v=1: 6$, soaking) at room temperature for $7 \mathrm{~d}$ per extraction. The extract was filtered and concentrated. This filtrate was separated with a vacuum column chromatograph (Silica gel, 200-300 items, Qingdao Haiyang Chemical Factory, Qingdao, Shandong, China) using a petroleum ether-ethyl acetate-methanol step gradient elution. The crude isoflavones were chromatographed using petroleum ether-ethyl acetate-methanol $(5: 1: 0.1, v / v)$. The ICS was standardized to $72.3 \%$ isoflavone content by weight (72.3 g of total isoflavones per $100 \mathrm{~g}$ of total extract) using a spectrophotometric method. An HPLC analysis of ICS showed that the percentages of 4 major isoflavones were as follows: 1) ononin, $7.7 \%$; 2 ) biochanin A-7-O- $\beta-D-$ glucoside, $13.2 \%$; 3) formononetin, $19.5 \%$; and 4) biochanin A, $31.9 \%$.

\section{Experimental design \\ Animals and treatments}

Ten-week-old specific pathogen-free (SPF) virgin female Sprague-Dawley (SD) rats (average body weight, 220 $\pm 10 \mathrm{~g}$ ) were purchased from the Experimental Animal Center of the Xinjiang Institute of Endemic Disease Prevention and Control. All of the rats were housed in an air-conditioned environment under a 12-h light and 12-h dark cycle, with a temperature of $23 \pm 1^{\circ} \mathrm{C}$ and a relative humidity of $50 \% \pm 3 \%$. All protocols were approved by the Animal Ethics Committee of Xinjiang Medical University.

After $3 \mathrm{~d}$ of acclimation, ovariectomy (OVX) was performed under ketamine general anesthesia. The rats were allowed to recover for 2 weeks after OVX. Forty-eight OVX rats were randomly divided into six groups ( $n=8$ rats/group) as follows: the sham-operated and vehicle (Sham-Veh) group, the OVXVeh group, the OVX $+E_{2}$ group $\left(E_{2} 0.25 \mathrm{mg} \cdot \mathrm{kg}^{-1} \cdot \mathrm{d}^{-1}\right.$, ig), the OVX+ICS-20 group (ICS $20 \mathrm{mg} \cdot \mathrm{kg}^{-1} \cdot \mathrm{d}^{-1}$, ig), the OVX+ICS-50 group (ICS $50 \mathrm{mg} \cdot \mathrm{kg}^{-1} \cdot \mathrm{d}^{-1}$, ig) and the OVX+ICS-100 group (ICS $100 \mathrm{mg} \cdot \mathrm{kg}^{-1} \cdot \mathrm{d}^{-1}$, ig). Powdered $\mathrm{E}_{2}$ and ICS were dissolved in corn oil. Daily intragastric gavage administration was performed with a different dosage for each group rats for a total of $35 \mathrm{~d}$.

\section{Uterine weight measurement}

On the morning of the 36th day of treatment, the rats were anesthetized, and their uteruses were quickly dissected and weighed. The standardized uterine index was calculated based on uterine wet weight-to-body weight ratios and multiplied by 100 .

\section{Serum hormone measurement}

Blood samples were collected from the abdominal aorta. The serum was separated by centrifugation at $1000 \times \mathrm{g}$ for $10 \mathrm{~min}$ and then stored at $-80^{\circ} \mathrm{C}$ until assay for $\mathrm{E}_{2}, \mathrm{FSH}$, and $\mathrm{LH}$. Serum $\mathrm{E}_{2}, \mathrm{FSH}$, and LH concentrations were determined using radioimmunoassay (RIA kits, BNIBT Corporation). 


\section{Histological analysis of uterus}

Each uterus was fixed in $4 \%$ paraformaldehyde overnight, dehydrated in a graded series of ethanol, cleared in xylene, and then embedded in a paraffin block with the left horn placed longitudinally and the right horn placed crosswise. The tissue blocks were cut into 4- $\mu$ m-thick sections, stained with hematoxylin $(\mathrm{H})$ and eosin $(\mathrm{E})$, and used for histological evaluation under a light microscope [Olympus BH2 Microscope (Olympus Corp, Tokyo, Japan)] coupled with an image analysis system (Southern Micro Instruments, Atlanta, GA, USA).

The epithelial height in the endometrium and the number of glands in the middle region of the uterus were assessed. The epithelial height was determined by obtaining three measurements from three areas of longitudinally embedded tissues from a minimum of three rats for each treatment (at least 27 measurements per treatment group). The number of glands was counted in three sections per rat from a minimum of three rats per treatment group in crosswise-embedded tissues (at least 27 counts per treatment group). The values from each animal were averaged, and the means were used to calculate the mean $\pm S E M$ for each group.

\section{Immunohistochemical uterine analysis}

Sequential 4 - $\mu \mathrm{m}$-thick paraffin sections were used for immunohistochemical analysis for PCNA. Briefly, sections were deparaffined in xylene for $60 \mathrm{~min}$ and then rehydrated. They were then boiled in $10 \mathrm{mmol} / \mathrm{L}$ citrate buffer for $15 \mathrm{~min}$ for antigen retrieval. The cooled sections were incubated in peroxidase blocking agent for $10 \mathrm{~min}$ to quench endogenous peroxidase and then washed with PBS for 5 min three times. To block the nonspecific binding of secondary antibodies, sections were incubated in the normal serum for $10 \mathrm{~min}$ at room temperature. Sections were then incubated with mice antiPCNA (1:100) overnight at $4^{\circ} \mathrm{C}$. The slides were washed with PBS and incubated with secondary antibody peroxidase conjugated goat anti-rabbit/mice (IgG) for $1 \mathrm{~h}$ at room temperature. After thorough washing in PBS, the sections were developed with 3,3'-diaminobenzidine substrate (Dako) and slightly counterstained with hematoxylin. Negative controls were incubated with 3\% BSA instead of primary antibody and were submitted to the same treatments as the experimental groups. The PCNA-positive nuclei rate in the luminal epithelial cells was determined by the ratio of positive PCNA-staining nuclei to total luminal epithelial cells and multiplied by 100 . Three areas of luminal epithelial cells, uterine stromal cells and glandular epithelial cells were counted in three sections per rat from a minimum of three rats per treatment group.

\section{Histological and microcomputed tomographic (Micro-CT)} analyses of bone

For histological analysis, the left femur of each rat was dissected and fixed in 10\% buffered formalin for $72 \mathrm{~h}$, decalcified in $10 \%$ EDTA ( $\mathrm{pH} \mathrm{7.0)}$ ) for $18 \mathrm{~d}$ and embedded in paraffin. Four-micrometer-thick cross-sections of bone, including the metaphysis and diaphysis, were processed for H\&E staining.
The number of multinucleated osteoclasts was determined in three sections from a minimum of three rats from each treatment group (at least 27 counts per treatment group).

For micro-CT scanning, the right femur was dissected free from soft tissue, fixed overnight in 70\% ethanol and analyzed using a high resolution micro-CT imaging system (ZKKSMCT-Sharp; Zhongke Kaisheng Medical Technology Co, Ltd, Guangzhou, China). The X-ray projection was set at a voltage of $70 \mathrm{kV}$ and a current of $428.6 \mu \mathrm{A}$. The resulting 2D longitude-sectional images or 3D whole-bone images were shown in grayscale, and the physical resolution was $50 \mu \mathrm{m}$. The scanned primary photographs had a 2240×2344-pixel resolution. Three-dimensional structural parameters were calculated, including total BMD: bone mineral density, BV/TV: trabecular bone volume to tissue volume, Tb.Th: trabecular thickness, and Tb.Sp: trabecular separation.

\section{Statistical analysis}

In each in vivo experiment, the rats were age- and weightmatched to minimize individual differences. The results were expressed as the mean \pm SEM. The primary statistical test was analysis of variance (ANOVA). When the overall $F$ test result of the ANOVA was significant, a multiple-comparison Tukey's test was applied. The Student's $t$-test was used in two-mean comparisons. Differences were reported as significant when $P$ values were $<0.05$.

\section{Results}

\section{Effect of ICS on uterine weight and serum hormonal levels}

Table 1 shows uterine index and serum $\mathrm{E}_{2}, \mathrm{FSH}$, and LH levels. The uterine index and $\mathrm{E}_{2}$ levels of the $\mathrm{OVX}+\mathrm{Veh}$ group were significantly decreased compared with those of the Sham-Veh group $(P<0.01)$. In contrast, the serum FSH and LH levels of the OVX+Veh group were significantly increased compared with those of the Sham-Veh group $(P<0.01) . \quad E_{2}$ treatment $\left(\mathrm{OVX}+\mathrm{E}_{2}\right)$ restored serum $\mathrm{E}_{2}, \mathrm{FSH}$, and $\mathrm{LH}$ to the same levels as in the Sham+Veh group. Furthermore, medium- and high-dose ICS treatment (OVX+ICS-50 and OVX+ICS-100) also restored serum $\mathrm{E}_{2}, \mathrm{FSH}$, and $\mathrm{LH}$ levels to the levels of the Sham + Veh and OVX $+\mathrm{E}_{2}$ rats, and the $\mathrm{E}_{2}$ and ICS 50 and 100 $\mathrm{mg} \cdot \mathrm{kg}^{-1} \cdot \mathrm{d}^{-1}$ treatment partially restored the uterine index to levels similar to those of the Sham+Veh group.

\section{Effects of ICS on uterine structure}

The response of uterine epithelial cell height to $\mathrm{E}_{2}$ and ICS seven weeks after OVX is presented in Figure 1A. The diagrams are drawn from photomicrographs of the magnification $(\times 100)$. As Figure $1 \mathrm{~B}$ shows, the treatment of rats with ICS (OVX+ICS-50 or OVX+ICS-100) was associated with a statistically significant increase in the uterine epithelial height of approximately $60 \%$ compared with the uteri of OVX-Veh rats, which demonstrated a similar pattern to that of $\mathrm{OVX}+\mathrm{E}_{2}$ treatment. The number of glands per cross section is statistically shown in Figure 1C. $\mathrm{E}_{2}$ and ICS rats had a significantly increased number of glands in the uterus compared with OVX+Veh rats. 
Table 1. Uterine index and serum $\mathrm{E}_{2}, \mathrm{FSH}$, and $\mathrm{LH}$ levels in $\mathrm{E}_{2}$ - or ICS-treated rats. Results are means $\pm S E M$. $n=8$ rats $/$ group. ${ }^{\mathrm{b}} P<0.05$, ${ }^{\mathrm{C}} P<0.01 \mathrm{vs}$ Sham-Veh group. ${ }^{\mathrm{e}} \mathrm{P}<0.05,{ }^{\mathrm{f}} \mathrm{P}<0.01$ vs $0 \mathrm{VX}$-Veh group.

\begin{tabular}{|c|c|c|c|c|}
\hline \multirow[b]{2}{*}{ Treatment } & \multirow{2}{*}{$\begin{array}{l}\text { Uterine index } \\
(\mathrm{mg} / \mathrm{g} \times 100)\end{array}$} & \multicolumn{3}{|c|}{ Level in serum } \\
\hline & & $\begin{array}{l}\text { 17ß-Estradiol } \\
(\mathrm{pg} / \mathrm{mL})\end{array}$ & $\begin{array}{c}\mathrm{FSH} \\
(\mathrm{mlU} / \mathrm{mL})\end{array}$ & $\begin{array}{c}\mathrm{LH} \\
(\mathrm{mlU} / \mathrm{mL})\end{array}$ \\
\hline Sham-Veh & $287.0 \pm 16.0$ & $24.5 \pm 1.9$ & $1.8 \pm 0.2$ & $1.2 \pm 0.2$ \\
\hline OVX-Veh & $136.7 \pm 12.0^{c}$ & $13.1 \pm 0.8^{c}$ & $3.3 \pm 0.3^{c}$ & $2.9 \pm 0.1^{c}$ \\
\hline $\mathrm{OVX}+\mathrm{E}_{2}$ & $196.3 \pm 71.0^{f}$ & $22.1 \pm 0.5^{\mathrm{e}}$ & $2.2 \pm 0.5^{\mathrm{e}}$ & $1.3 \pm 0.1^{\mathrm{e}}$ \\
\hline OVX+ICS-100 & $186.1 \pm 11.3^{\mathrm{e}}$ & $19.4 \pm 1.1^{\mathrm{e}}$ & $2.4 \pm 0.6^{\mathrm{e}}$ & $1.5 \pm 0.1^{f}$ \\
\hline
\end{tabular}

Sham-Veh: Sham operated and vehicle treated group; OVX-Veh: Ovariectomized and vehicle treated group; OVX+E $\mathrm{E}_{2}: \mathrm{OVX}$ and $\mathrm{E}_{2}\left(0.25 \mathrm{mg} \cdot \mathrm{kg}^{-1} \cdot \mathrm{d}^{-1}\right.$, ig)

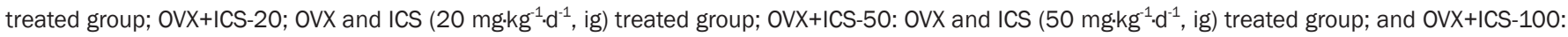
OVX and ICS (100 $\mathrm{mg}^{\mathrm{kg}} \cdot \mathrm{d}^{-1}$, ig) treated group.

\section{Effect of ICS on PCNA expression in the uterus}

Figure 2 shows $E_{2}$ or ICS treatments for 5 weeks induced PCNA expression in luminal epithelial cells, glandular epithelial cells and stromal cells in uterine. $E_{2}$ treatment increased PCNA expression, and medium and high doses of ICS had similar effects (Figure 2A). The PCNA-positive nuclei rate in luminal epithelial cells in OVX+Veh rats was $3.2 \% \pm 0.2 \%$; this rate was significantly increased in $\mathrm{OVX}+\mathrm{E}_{2}$ rats $(65.3 \% \pm 2.3 \%)$. ICS treatment resulted in a dose-dependent increase in the number PCNA-positive cells in luminal epithelial cells. The PCNA-positive cell ratio ranged from $9.0 \% \pm 0.5 \%$ to $45.6 \% \pm 1.8 \%$ (Figure $2 \mathrm{~B}$ ).

The stromal cell counts in the uterus ranged from $4.4 \% \pm 0.5 \%$ in OVX-Veh to $25.1 \% \pm 2.4 \%$ in $\mathrm{E}_{2}$ - and ICS-100- $(15.6 \% \pm 1.8 \%)$ treated tissues. The PCNA-positive nuclei rate in glandular epithelial cells was similar to that in luminal epithelial cells (data not shown).

\section{Effect of ICS on bone structure}

Total BMD and BV/TV in femur were significantly reduced by OVX (OVX+Veh rats vs Sham+Veh rats). The bone loss caused by OVX was restored by $\mathrm{E}_{2}\left(\mathrm{OVX}+\mathrm{E}_{2}\right)$ and ICS $(\mathrm{OVX}+\mathrm{ICS}-50$ and OVX+ICS-100) treatments (Figures $3 \mathrm{~A}$ and $3 \mathrm{~B}$ ). The potency of ICS-50 and ICS-100 was similar to that of $E_{2}$. The histomorphometric analysis of trabecular bone showed that Tb.Th was significantly decreased and that Tb.Sp was significantly increased in OVX+Veh rats compared with those measurements in Sham+Veh rats. Medium and high doses of ICS had effects that were similar to but weaker than those of $E_{2}$ for restoring the bone loss and structural changes caused by OVX (Figures 3C and 3D). The number of multinucleated osteoclasts was significantly less in the bones from $\mathrm{E}_{2}\left(\mathrm{OVX}+\mathrm{E}_{2}\right)$ and ICS (OVX+ICS-50 and OVX-ICS-100) rats compared with those of OVX+Veh rats (Figures $3 \mathrm{E}$ and $3 \mathrm{~F}$ ).

\section{Discussion}

This study has shown for the first time that the oral administration of ICS has significant estrogenic effects in OVX rats, including dose-dependently increasing uterine weight, restor- ing the uterine structure and circulating $\mathrm{E}_{2}, \mathrm{FSH}$, and LH levels, and preventing bone loss due to $E_{2}$ deficiency. Although the uterotrophic effects of high doses of ICS were weaker than the effects of $E_{2}$ in OVX rats, the significant estrogenic activity of ICS demonstrated that it contained strong phytoestrogens and could be used as an alternative therapy to relieve menopausal symptoms and prevent bone loss caused by estrogen deficiency during menopause.

The uterotrophic assay is a standard tool for determining the estrogenic activity of a given substance in vivo ${ }^{[18]}$. In the current study, young OVX female SD rats were used as the experimental model because SD female rats are more sensitive to estrogen than other strains of rats. These rats were euthanized after 5 weeks of treatment with $\mathrm{E}_{2}$ or ICS. The results showed that ICS dose-dependently increased uterine weight, indicating that ICS contained strong estrogen-like compounds.

Previous studies have shown that the isoflavone genistein had significant effects on uterine epithelial height and gene expression $^{[19,20]}$. To further confirm the uterotrophic effects of ICS, we examined the epithelial cell height, number of glands, and expression of PCNA in the uterus. The results showed that ICS at doses of 50 and $100 \mathrm{mg} \cdot \mathrm{kg}^{-1} \cdot \mathrm{d}^{-1}$ significantly increased the epithelial cell height, the number of glands on the uterine wall and the expression of PCNA in epithelial and stroma cells. These results further demonstrated that ICS has a direct estrogenic effect on the uterus.

It has been reported that phytoestrogens have the beneficial effect of restoring the profile of such sex hormones as $\mathrm{E}_{2}, \mathrm{FSH}$, and LH in women. The phytoestrogen genistein has been reported to enhance serum estrogen levels in OVX rats ${ }^{[21]}$, and phytoestrogen isolated from Pueraria mirifica has been reported to dose-dependently reduce serum levels of FSH and LH in rats $^{[22]}$. FSH and LH are key stimulators for follicular development. FSH stimulates small follicles to grow and mature, and LH is essential to the final growth of antral follicles. The preovulation secretion of FSH and $\mathrm{LH}$ is negatively regulated by circulating $E_{2}$ via the feedback control system of the hypothalamic-pituitary-ovarian axis ${ }^{[23]}$. In the current study, ICS at doses of 50 and $100 \mathrm{mg} \cdot \mathrm{kg}^{-1} \cdot \mathrm{d}^{-1}$ significantly increased serum 
A
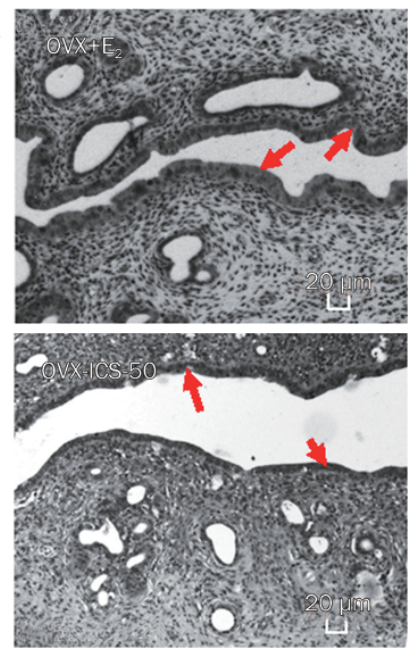

B

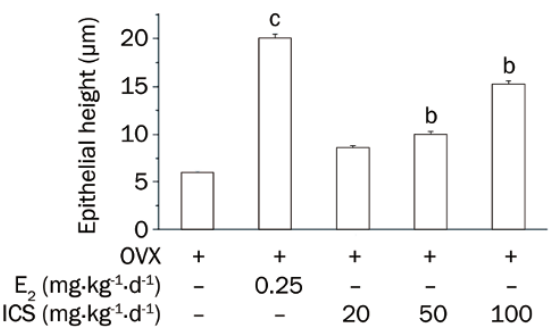

C

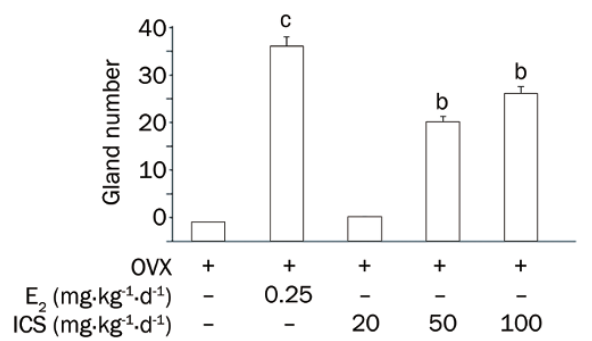

Figure 1. Uterine structure analysis. (A) Representative micrographs of sections of uteri of $O V X+E_{2}, O V X+I C S-100$, OVX+ICS-50, and $O V X+V$ eh rats. The arrow indicated area was the uterine epithelial layer (HE staining, $\times 100$ ). (B) Average urterine epithelial cell height, and (C) average uterine gland numbers of experimental groups. Results are means \pm SEM. $n=8$ rats/group. ${ }^{\mathrm{b}} P<0.05,{ }^{\mathrm{C}} P<0.01$ vs $\mathrm{OVX}+\mathrm{Veh}$ group.

$\mathrm{E}_{2}$ levels and attenuated the elevated serum LH and FSH levels resulting from the removal of $\mathrm{E}_{2}$ in OVX rats, indicating that ICS has a beneficial role in regulating hypothalamic-pituitary function.

Phytoestrogens have been shown to have beneficial effects on bone protection. For example, daidzein, genistein, and glycitein have been found to prevent femoral bone loss and maintain mechanical strength ${ }^{[24]}$. The administration of an isoflavone combination extracted from red clover for a 6-month period significantly increased the cortical bone of the proximal radius and ulna ${ }^{[25]}$. In our study, we measured four important indices of bone density and structure using micro-CT. The results indicated that ICS dose-dependently increased BMD,
A
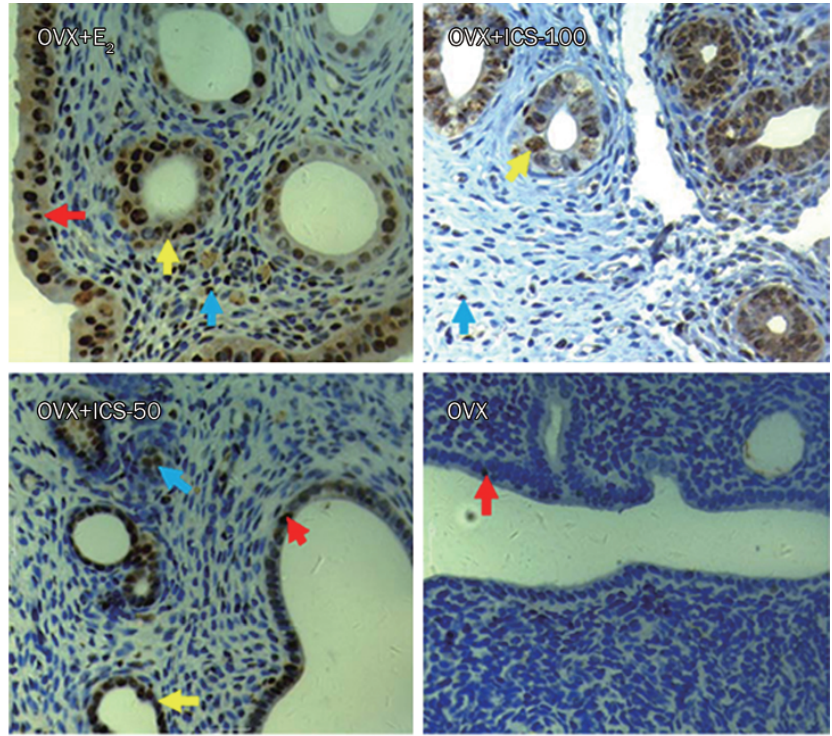

B

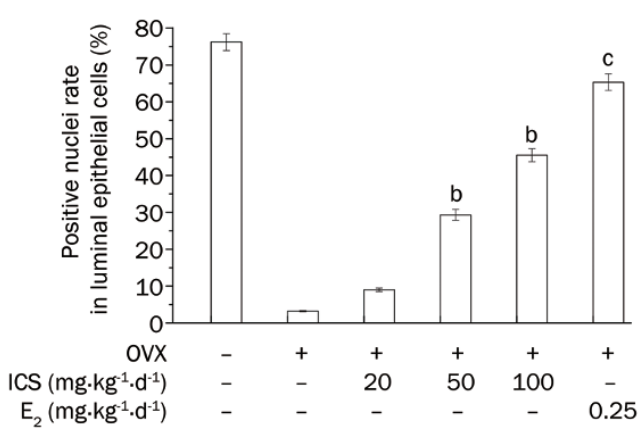

Figure 2. Immunohistochemical analysis of PCNA expression in uteri of OVX rats. (A) Representative micrographs of PCNA expression (brown staining in nuclei) in uteri of $\mathrm{OVX}+\mathrm{E}_{2}, \mathrm{OVX}+\mathrm{ICS}-50, \mathrm{OVX}+\mathrm{ICS}-100$, and $\mathrm{OVX}+\mathrm{Veh}$ rats. The color arrows indicated the positive nuclei in different cells: luminal epithelial cells (red arrows), glandular epithelial cells (yellow arrows) and stromal cells (blue arrows) in uterine $(\times 400)$. (B) Mean percent ratios of number of PCNA positive nuclei vs total number of the luminal epithelial cells nuclei in uteri. Results are means \pm SEM. $n=8$ rats/group. ${ }^{\mathrm{b}} \mathrm{P}<0.05,{ }^{\mathrm{c}} \mathrm{P}<0.01$ vs $\mathrm{OVX}+\mathrm{Veh}$ group.

BV/TV, and Tb.Th and decreased Tb.Sp. The effect of high doses of ICS was similar to that of $E_{2}$, suggesting that ICS stimulated bone formation and increased bone mineral content in the femurs of OVX rats. Previous investigators have demonstrated that bone loss caused by estrogen deficiency is mainly driven by an increase in osteoclastic bone resorption, and treatment with soybean isoflavones inhibits bone resorption ${ }^{[26]}$. Our results showed that administering a high dose of ICS to OVX rats significantly decreased osteoclast density, suggesting a positive effect of ICS on bone metabolism.

In summary, we demonstrate that ICS had strong estrogenic activity and it can be used to treat symptoms associated with menopause, restore endocrine function and prevent osteoporosis. This study provides a scientific basis for the use of ICS to prevent and treat estrogen deficiency-related diseases. 

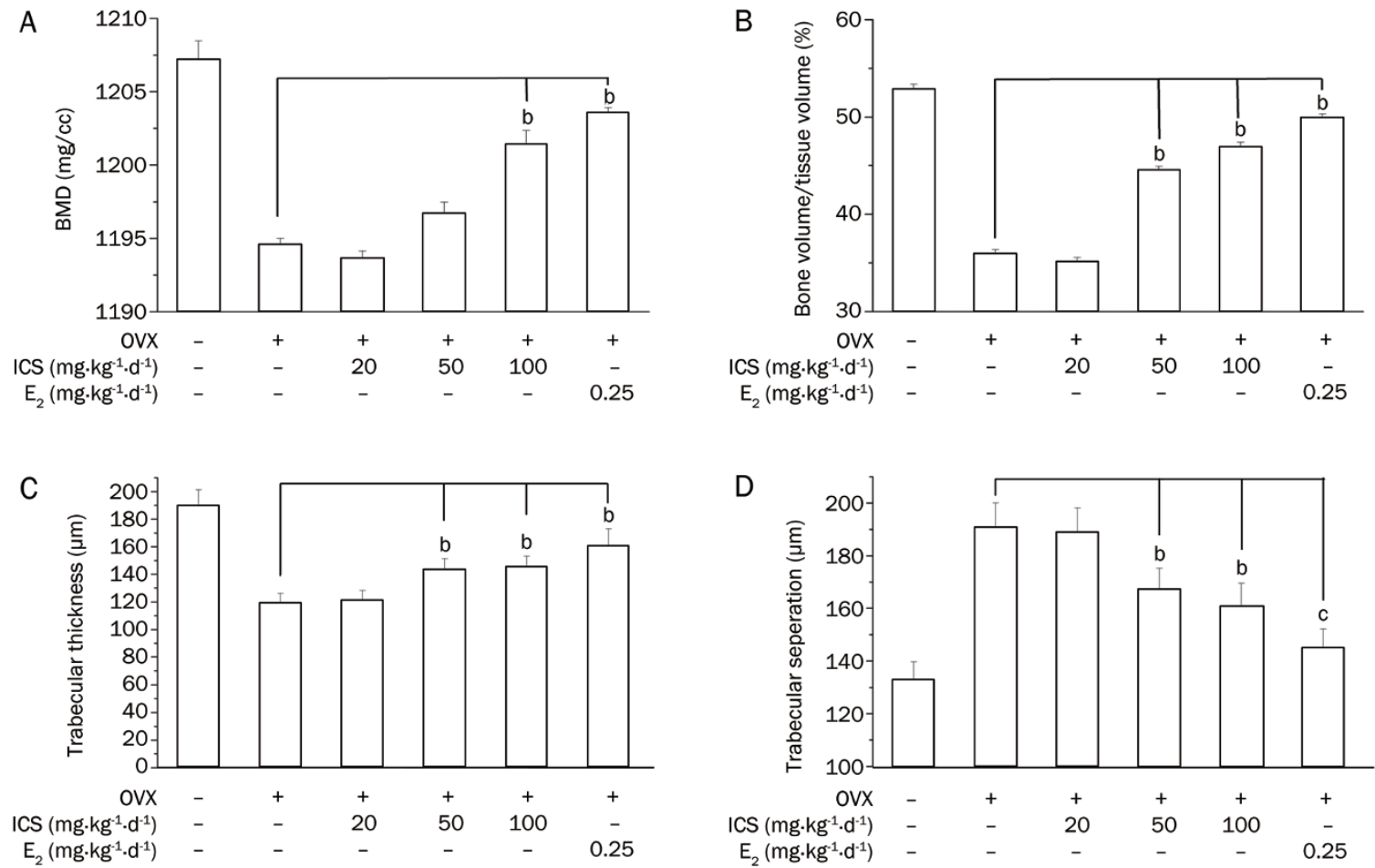

\section{$\mathrm{E}$}
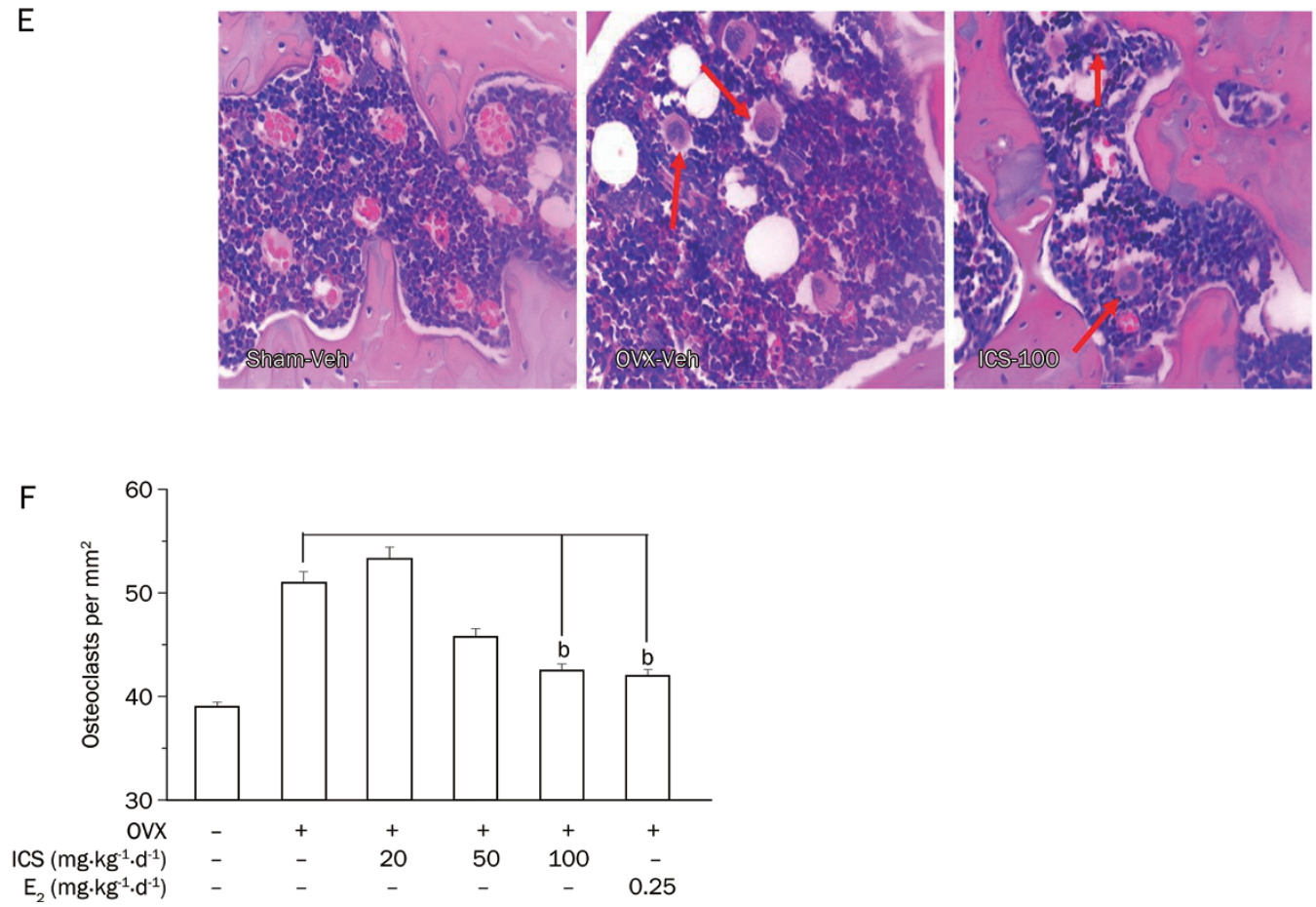

Figure 3. Histological analysis of the bone in the right distal femora, in Sham+Veh and OVX+Veh rats, as well as in OVX rats treated with E2 or ICS for 5 weeks. The femora were collected 7 weeks after OVX and 3D bone structure parameters were measured by Micro-CT. (A) Total bone mineral density (BMD); (B) Total bone volume to tissue volume ratios (BV/TV); (C) Trabecular thickness (Tb.Th); (D) Trabecular separation (Tb.Sp). (E) Representative micrographs to show distribution of multinucleated osteoclasts in bone (H\&E staining, red arrow indicated); and (F) Average of osteoclast density in bone ( $\times 400)$. Results are means \pm SEM. $n=8$ rats/group. ${ }^{b} P<0.05$ compared to $O V X+V$ eh group.

\section{Acknowledgements}

We thank Ying-qin LI, Hai-qing ZHAO, Yan-hong LI, Chun- fang LU, and Mei MA at the Animal Experimental Center, First Teaching Hospital Xinjiang Medical University for their 
assistance with rat surgery. We thank Prof Yiu-fai CHEN of the University of Alabama for language revision of the manuscript. This work was supported in part by grants from the China National Funds for Distinguished Young Scientists (Grant No 30925045), National Natural Science Foundation of China (Grant № 81102890), CAS/SAFEA International Partnership Program for Creative Research Teams (Grant No KGCX2-YW-503) and Natural Science Foundation of Xinjiang Province, China (Grant № 2010211A58).

\section{Author contribution}

Hai-rong MA participated in designing the study, preparing the experimental protocols, analyzed the data and wrote the paper. Jie WANG performed the immunohistochemical experiments; Hong-xue QI and Ming-jun DUAN performed the procedures related to animal raising and OVX modeling. Yanhua GAO and Yi YANG performed the procedures related to the ICS preparation and assay. Hua CHEN performed serum hormone measurement. Li-juan PANG offered the help to establish the protocols. Zhen-hua WANG helped to analyze the data. Xu CAO and Haji Akber AISA designed the study and analyzed the data.

\section{References}

1 Bryant HU, Dere WH. Selective estrogen receptor modulators: an alternative to hormone replacement therapy. Proc Soc Exp Biol Med 1998; 217: 45-52.

2 Manolagas SC. Birth and death of bone cells: Basic regulatory mechanisms and implications for the pathogenesis and treatment of osteoporosis. Endocrine Rev 2000; 21: 115-37.

3 Newton KM, Grady D. Soy isoflavones for prevention of menopausal bone loss and vasomotor symptoms. Arch Int Med 2011; 171: 136970.

4 Waldman TN. Menopause: When hormone replacement therapy is not an option. Part II. J Women Health 1998; 7: 673-83.

5 Barnabei VM, Grady D, Stovall DW, Cauley JA, Lin F, Stuenkel CA, et al. Menopausal symptoms in older women and the effects of treatment with hormone therapy. Obstetric Gynecol 2002; 100: 1209-18.

6 Mei J, Yeung SSC, Kung AWC. High dietary phytoestrogen intake is associated with higher bone mineral density in postmenopausal but not premenopausal women. J Clin Endocrinol Metab 2001; 86: 5217-21.

7 Steinberg FM, Murray MJ, Lewis RD, Cramer MA, Amato P, Young RL, et al. Clinical outcomes of a 2-yr soy isoflavone supplementation in menopausal women. Am J Clin Nutr 2011; 93: 356-67.

8 Dornstauder E, Jisa E, Unterrieder I, Krenn L, Kubelka W, Jungbauer A. Estrogenic activity of two standardized red clover extracts Menoflavon $\AA$ intended for large scale use in hormone replacement therapy. J Steroid Biochem Mol Biol 2001; 78: 67-75.

9 Polan ML, Hochberg RB, Trant AS, Wuh HCK. Estrogen bioassay of ginseng extract and Arginmax ${ }^{\circledR}$, a nutritional supplement for the enhancement of female sexual function. J Womens Health 2004; 13 : 427-30.

10 Circosta C, De Pasquale R, Palumbo DR, Samperi S, Occhiuto F.
Estrogenic activity of standardized extract of Angelica sinensis. Phytother Res 2006; 20: 665-9.

11 White PJ, Broadley MR. Biofortification of crops with seven mineral elements often lacking in human diets - iron, zinc, copper, calcium, magnesium, selenium and iodine. New Phytologist 2009; 182: 4984.

12 Liu YM, Yikemu S. Wei Wu Er Yao Zhi. 1st ed. Urumqi (Xinjiang): Xin Jiang People's Publishing House; 1986. p 469-71.

13 Zhao S, Zhang L, Gao P, Shao Z. Isolation and characterisation of the isoflavones from sprouted chickpea seeds. Food Chem 2009; 114: 869-73.

14 Cheng Z, Ayiguli A, Ma Q, Gao Y, Aisa HA. Determination of isoflavones in extracts of cicer afiefinum $L$ and bean sprout by ultrabiolet spectrophotometry. Lishizhen Med Mater Med Res 2008; 19: 2612-3.

15 Lv Q, Yang Y, Zhao Y, Gu D, He D, Yili A, et al. Comparative study on separation and purification of isoflavones from the seeds and sprouts of chickpea by high-speed countercurrent chromatography. J Liq Chromatogr R T 2009; 32: 2879-92.

16 Zava DT, Dollbaum CM, Blen M. Estrogen and progestin bioactivity of foods, herbs, and spices. Proc Soc Exp Biol Med 1998; 217: 369-78.

17 Wei H, Yili A, Ma Q, Mai D, Wang Z, Ma H. Establishment and application of co-transfection screening method for phytoestrogen active constituents. Zhongguo Zhong Yao Za Zhi 2011; 36: 2530-4.

18 Diel P, Schulz T, Smolnikar K, Strunck E, Vollmer G, Michna H. Ability of xeno- and phytoestrogens to modulate expression of estrogensensitive genes in rat uterus: estrogenicity profiles and uterotropic activity. J Steroid Biochem Mol Biol 2000; 73: 1-10.

19 Diel P, Smolnikar K, Schulz T, Laudenbach-Leschowski U, Michna H, Vollmer G. Phytoestrogens and carcinogenesis - differential effects of genistein in experimental models of normal and malignant rat endometrium. Hum Reprod 2001; 16: 997-1006

20 Möller FJ, Diel P, Zierau O, Hertrampf T, Maass J, Vollmer G. Longterm dietary isoflavone exposure enhances estrogen sensitivity of rat uterine responsiveness mediated through estrogen receptor $\alpha$. Toxicol Lett 2010; 196: 142-53.

$21 \mathrm{Li} \mathrm{W}$, Liu YH. Effects of phytoestrogen genistein on genioglossus function and oestrogen receptors expression in ovariectomized rats. Arch Oral Biol 2009; 54: 1029-34.

22 Malaivijitnond S, Kiatthaipipat P, Cherdshewasart W, Watanabe G, Taya K. Different effects of Pueraria mirifica, a herb containing phytoestrogens, on $\mathrm{LH}$ and FSH secretion in gonadectomized female and male rats. J Pharmacol Sci 2004; 96: 428-35.

23 Arai K, Komura H, Akikusa T, lio K, Kishi H, Watanabe G, et al. Contributions of endogenous inhibin and estradiol to the regulation of follicle-stimulating hormone and luteinizing hormone secretion in the pregnant rat. Biol Reproduction 1997; 56: 1482-89.

24 Ishida H, Uesugi T, Toda T, Tsuji K. Effects of soy isoflavones, daidzein, genistein and glycitein, on bone loss and lipid metabolic pathway in ovariectomized rats. J Nutr 2000; 130: 685S-6S.

25 Clifton-Bligh PB, Baber RJ, Fulcher GR, Nery ML, Moreton T. The effect of isoflavones extracted from red clover (Rimostil) on lipid and bone metabolism. Menopause 2001; 8: 259-65.

26 Wang XX, Wu J, Chiba H, Umegaki K, Yamada K, Ishimi Y. Puerariae radix prevents bone loss in ovariectomized mice. J Bone Mine Metab 2003; 21: 268-75. 